\title{
柴达木北缘榴辉岩中的柯石英及其意义
}

\author{
张建新 ${ }^{(1}$, 孟繁聪 $^{(1}$, 李金平 ${ }^{(1)}$, Mattinson C. G. ${ }^{(2)}$ \\ (1) 中国地质科学院地质研究所, 北京 100037 ; \\ (2) Department of Geological Sciences, Central Washington University, 400 E. University Way, Ellensburg, WA 98926, USA \\ E-mail:zjx66@yeah.net
}

2008-09-03 收稿, 2008-12-22 接受

国家自然科学基金项目(批准号: 40772138, 40472102, 40272095)、国土资源部百名优秀青年人才计划及中国地质调查局地质调查项目(编号: 1212010611811)资助

Zhang J X, Meng F C, Li J P, et al. Coesite in eclogite from the North Qaidam Mountains and its implications.

Chinese Science Bulletin, 2009, 54, doi: 10.1007/s11434-009-0074-x

摘要 柯石英是超高压变质作用的直接标志. 柴北缘副片麻岩的锆石中已报道有柯石英包体的存 在, 但在榴辉岩中还没有发现柯石英保存. 通过详细的岩相学观察和拉曼光谱的测定, 在柴北缘阿 尔茨托山(都兰超高压变质单元南带)的榴辉岩中发现柯石英, 这些柯石英在石榴子石中呈包体分 布, 部分被具有柱状结构的石英替代. 这是柴北缘地区首次在榴辉岩中发现柯石英, 也与榴辉岩 关键词 柴北缘 榴辉岩 柯石英 $670 \sim 730^{\circ} \mathrm{C}$ 和 2.7 3.25 GPa 的温压估算相符合. 除柴北缘都兰超高压单元之外, 柴北缘其他单元的 榴辉岩及相关岩石中还没有发现柯石英及其假象, 是否柴北缘普遍经历过超高压变质作用还需进 一步研究.

超高压(UHP)变质作用是指变质条件稳定在柯 石英-石英转变线之上的变质作用, 因此, 虽然近年 来新发展出许多用于判定岩石是否经历了超高压变 质作用的标志, 但柯石英仍然是 UHP 变质作用的最 主要和最直接的标志之一.

柴北缘 $\mathrm{HP} / \mathrm{UHP}$ 变质带是近 10 年来在中国西部 所新厘定 $\stackrel{[1 \sim 13]}{ }$, 它向西越过阿尔金断裂延至南阿尔金, 被认为是继大别-苏鲁之后, 在中国出露的又一个被 巨型走滑断裂所切割的HP/UHP变质带 ${ }^{[14 ~ 21]}$. 然而, 与大别-苏鲁地区不同，在柴北缘和南阿尔金地区， 目前所发现的UHP变质作用证据还相对较少, 到目 前为止, 仅仅在柴北缘东段都兰地区角闪岩相副片 麻岩的锆石中发现有少量柯石英包体, 而在榴辉岩 中, 除在南阿尔金江尔勒萨依和柴北缘的都兰地区

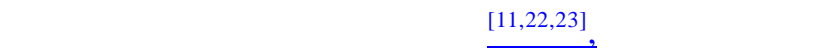
切的柯石英存在. 虽然多晶石英包体普遍被认为是 柯石英的假象，但由于南阿尔金和在柴北缘发现的 多晶石英集合体中还有少量的钾长石，一些学者认
为其不能简单解释成柯石英假象 $[24,25]$.

最近, 我们通过对柴北缘都兰地区阿尔茨托山 北坡新发现榴辉岩的详细薄片观察, 在榴辉岩中的 石榴子石中发现了典型的柯石英包体残留, 这是在 柴北缘 HP/UHP 带中, 第一次在榴辉岩中发现柯石 英.

\section{1 地质背景}

柴北缘HP-UHP变质带的分布西起绿梁山西端的 鱼卡-落凤坡地区, 东至都兰北部的野马滩-沙柳河地 区, 从西向东可分为鱼卡-落凤坡榴辉岩-片麻岩单 元、绿粱山石榴橄榄岩-高压麻粒岩单元、锡铁山榴 辉岩-片麻岩单元、都兰榴辉岩-片麻岩单元 ${ }^{[21]}$. 都兰 榴辉岩-片麻岩单元主要由花岗质片麻岩、副片麻岩 (片岩)、呈透镜状产在片麻岩中的榴辉岩和少量蛇纹 石化超基性岩所组成. 根据岩石组合和形成的 $P-T$ 条 件等进一步分为北亚带和南亚带 $[3,11]$ ，两者之间被野 马滩花岗岩体所分隔. 北亚带的榴辉岩研究较多, 其 
主要由石榴子石+绿辉石+金红石土多硅白云母所组 成, 石榴子石中具有多晶石英+钾长石(透长石)组成 的包体(柯石英假像), 绿辉石中有石英棒的出溶结构 [23], 这些结构特征被认为是超高压变质作用的标志, 估算的榴辉岩峰期变质条件为 $P>2.8 \mathrm{GPa}, T=600 \sim$ $750^{\circ} \mathrm{C}^{[11]}$; 在北亚带的副片麻岩锆石中发现有少量柯 石英包体 ${ }^{[4,11,13]}$. 南亚带的榴辉岩研究较少, 目前所 发现的榴辉岩以含蓝晶石为特征, 部分榴辉岩含有 多硅白云母 ${ }^{[11,15]}$ ，所估算的榴辉岩形成的温压条件 也在柯石英稳定线之上, 并有少量柯石英假象的报 道 ${ }^{[15]}$, 但在本文之前, 还没有发现柯石英.

\section{2 含柯石英榴辉岩的基本特征}

具有柯石英的榴辉岩取自于柴北缘东段的阿尔茨 托山(图 1), 属于柴北缘都兰HP/UHP变质单元的南亚带 [3,11]. 榴辉岩呈透镜状产在含白云母的长英质片麻岩中, 通过对近 20 个榴辉岩样品的详细岩相学观察, 在其中两 个新鲜榴辉岩样品(Q07-8-2.2 和Q07-8-2.3)中发现有柯 石英残留, 这两个样品榴辉岩主要由石榴子石、绿辉石、 多硅白云母和金红石组成, 具有微量的磷灰石和锆石, 其含量达 3\% 5\%的多硅白云母明显不同于都兰HP/UHP 单元的其他榴辉岩. 含柯石英榴辉岩具有明显的叶理,
由定性分布的石榴子石、绿辉石、多硅白云母所构成, 其 中石榴子石具不规则椭圆状, 电子探针分析表明其没有 明显的成分环带, 样品Q07-8-2.3 的石榴子石成分为: $\operatorname{Prp}_{16-18} \mathrm{Alm}_{53-55} \mathrm{GrO}_{28-30} \mathrm{Sps}_{1-1.2}$ (除标注外, 本文的矿物英 文缩写据文献[26]), 样品Q07-8-2.2 的石榴子石成分为: $\operatorname{Prp}_{20-23} \mathrm{Alm}_{47-50} \mathrm{GrO}_{27-30} \mathrm{Sps}_{1-1.3}$; 绿辉石的硬玉分子含量为 $37 \mathrm{~mol} \%$ 50 mol\%, 其中样品Q07-8-2.3 中绿辉石的硬玉 分子含量明显大于样品Q07-8-2.2; 多硅白云母的硅原子 数为 6.88 7.03(基于 22 个氧原子)(表 1).

\section{3 柯石英的显微结构特征及拉曼光谱分析}

图 2 展示了榴辉岩中石榴子石保存的柯石英残 留和绿辉石中保存的柯石英假象. 从图 2 中可以看出, 高突起的柯石英呈残晶保存在石榴子石包体的中心, 而边部已变成低突起的石英, 且边部具有典型的棚 状结构特征. 我们对不同保存程度的柯石英的进行 了详细的拉曼光谱分析, 拉曼光谱分析在国土资源 部大陆动力学实验室进行, 所用仪器型号为 RENISHAW RM1000, 激光器为 $514 \mathrm{~nm}$. 分析结果展 示在图 3 中, 可以看出颗粒较大、保存较好的柯石英 的拉曼光谱的柯石英峰(522 和 271)非常强, 而石英 的峰相对较弱; 而颗粒细小的柯石柯石英残晶的拉

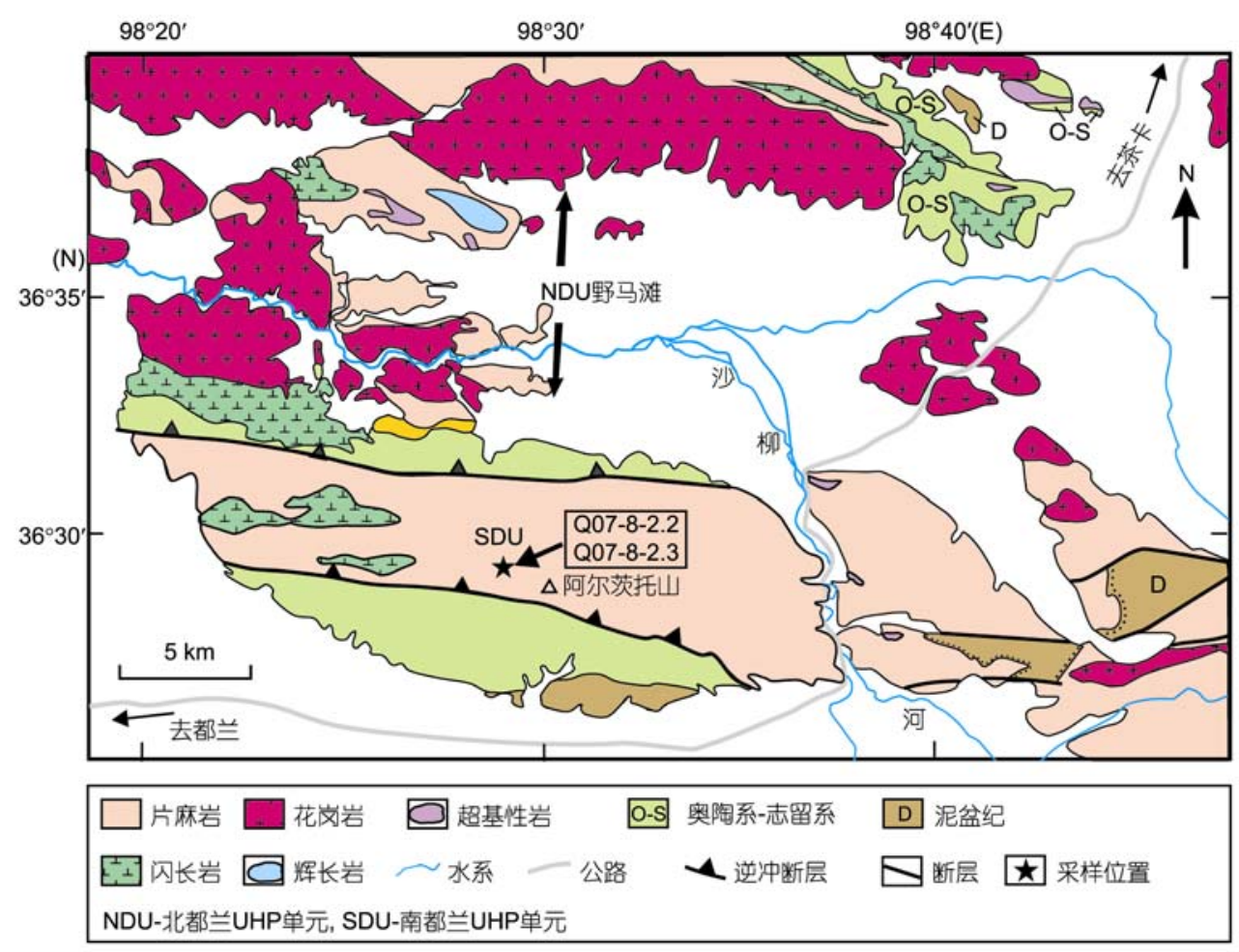

图 1 都兰 UHP 变质单元地质简图及取样位置 
表 1 含柯石英榴辉岩的代表性矿物成分 ${ }^{\text {a) }}$

\begin{tabular}{|c|c|c|c|c|c|c|c|c|c|c|c|c|c|c|c|c|c|c|}
\hline 样品 & & & & & 207-8 & & & & & & & & & 207-8 & & & & \\
\hline 矿物 & Grt & Omp & Phe & Grt & Omp & Phe & Grt & Omp & Phe & Grt & Omp & Phe & Grt & Omp & Phe & Grt & Omp & Phe \\
\hline $\mathrm{SiO}_{2}$ & 37.64 & 55.46 & 53.89 & 37.97 & 54.79 & 52.66 & 37.49 & 55.28 & 51.92 & 38.45 & 55.46 & 52.65 & 38.79 & 54.78 & 52.46 & 38.04 & 55.1 & 51.86 \\
\hline $\mathrm{TiO}_{2}$ & 0.25 & 0.16 & 0.73 & 0.12 & 0.19 & 0.72 & 0.05 & 0.20 & 0.68 & 0.03 & 0.05 & 0.71 & 0.03 & 0.08 & 0.77 & 0.08 & 0.09 & 0.79 \\
\hline $\mathrm{Al}_{2} \mathrm{O}_{3}$ & 21.62 & 10.87 & 25.24 & 21.50 & 10.50 & 25.05 & 21.44 & 11.05 & 26.23 & 21.57 & 9.23 & 24.91 & 21.64 & 9.75 & 25.48 & 21.47 & 9.41 & 25.45 \\
\hline $\mathrm{Cr}_{2} \mathrm{O}_{3}$ & 0.00 & 0.00 & 0.00 & 0.03 & 0.00 & 0.00 & 0.04 & 0.02 & 0.00 & 0.00 & 0.00 & 0.00 & 0.00 & 0.00 & 0.00 & 0.00 & 0.04 & 0.02 \\
\hline $\mathrm{FeO}$ & 25.54 & 5.91 & 2.67 & 25.09 & 6.24 & 2.82 & 25.54 & 6.15 & 2.94 & 22.38 & 4.05 & 1.43 & 22.79 & 4.43 & 1.62 & 22.87 & 4.31 & 1.49 \\
\hline $\mathrm{MnO}$ & 0.43 & 0.06 & 3.99 & 0.50 & 0.00 & 0.00 & 0.47 & 0.00 & 0.01 & 0.47 & 0.04 & 0.00 & 0.40 & 0.05 & 0.00 & 0.48 & 0.00 & 0.00 \\
\hline $\mathrm{MgO}$ & 4.43 & 7.25 & 0.00 & 4.00 & 7.15 & 3.90 & 4.13 & 7.32 & 3.66 & 5.68 & 9.26 & 4.21 & 5.95 & 9.57 & 4.14 & 5.78 & 9.34 & 4.42 \\
\hline $\mathrm{CaO}$ & 9.80 & 12.82 & 0.02 & 10.75 & 12.59 & 0.01 & 10.03 & 12.92 & 0.00 & 10.46 & 15.41 & 0.02 & 9.58 & 16.05 & 0.00 & 10.31 & 15.70 & 0.03 \\
\hline $\mathrm{Na}_{2} \mathrm{O}$ & 0.00 & 7.22 & 0.00 & 0.00 & 7.32 & 0.29 & 0.00 & 7.30 & 0.31 & 0.00 & 5.76 & 0.30 & 0.00 & 5.41 & 0.33 & 0.00 & 5.89 & 0.35 \\
\hline $\mathrm{K}_{2} \mathrm{O}$ & 0.00 & 0.00 & 10.28 & 0.00 & 0.00 & 10.6 & 0.00 & 0.00 & 31 & 0.00 & 0.00 & 44 & 0.00 & 0.00 & 10.62 & 0.00 & 0.00 & 10.75 \\
\hline 总量 & 99.71 & 99.75 & 97.13 & 99.96 & 98.78 & 96.05 & 99.19 & 100.24 & 06 & 04 & 6 & 67 & 99.18 & 100.12 & 95.42 & 99.03 & 38 & .16 \\
\hline $\mathrm{Si}$ & 2. & 982 & 33 & 2 & $\gamma$ & & 2. & 5 & 30 & 99 & & & 4 & D6 & 63 & 7 & 67 & 15 \\
\hline $\mathrm{Al}$ & 2.002 & 0.458 & 3.883 & 1.987 & 0.446 & 3.915 & 1.999 & 0.464 & 4.096 & 1.983 & 0.391 & 3.819 & 1.982 & 0.410 & 3.986 & 1.980 & 0.396 & 4.000 \\
\hline $\mathrm{Ti}$ & 0.015 & 0.004 & 0.072 & 0.007 & 0.005 & 0.072 & 0.003 & 0.005 & 0.068 & 0.002 & 0.001 & 0.071 & 0.002 & 0.002 & 0.077 & 0.005 & 0.002 & 0.079 \\
\hline $\mathrm{Cr}$ & 0.000 & 0.000 & 0.000 & 0.002 & 0.000 & 0.000 & 0.003 & 0.001 & 0.000 & 0.000 & 0.000 & 0.000 & 0.000 & 0.000 & 0.000 & 0.000 & 0.001 & 0.002 \\
\hline $\mathrm{Fe}^{3+}$ & 0.000 & 0.043 & 0.000 & 0.000 & 0.066 & 0.000 & 0.000 & 0.040 & 0.000 & 0.000 & 0.010 & 0.000 & 0.000 & 0.000 & 0.000 & 0.000 & 0.011 & 0.000 \\
\hline $\mathrm{Fe}^{2+}$ & 1.678 & 0.134 & 0.291 & 1.645 & 0.123 & 0.313 & 1.690 & 0.143 & 0.326 & 1.460 & 0.111 & 0.160 & 1.481 & 0.132 & 0.180 & 1.497 & 0.118 & 0.166 \\
\hline $\mathrm{Mn}$ & 0.029 & 0.002 & 0.000 & 0.033 & 0.000 & 0.000 & 0.031 & 0.000 & 0.001 & 0.031 & 0.001 & 0.000 & 0.026 & 0.002 & 0.000 & 0.000 & 0.000 & 0.000 \\
\hline $\mathrm{Mg}$ & 0.519 & 0.386 & 0.776 & 0.467 & 0.385 & 0.771 & 0.487 & 0.388 & 0.723 & 0.660 & 0.496 & 0.837 & 0.689 & 0.509 & 0.819 & 0.674 & 0.497 & 0.878 \\
\hline $\mathrm{Ca}$ & 0.825 & 0.491 & 0.003 & 0.903 & 0.485 & 0.001 & 0.850 & 0.492 & 0.000 & 0.874 & 0.595 & 0.003 & 0.798 & 0.614 & 0.000 & 0.864 & 0.600 & 0.000 \\
\hline $\mathrm{Na}$ & 0.000 & 0.500 & 0.081 & 0.000 & 0.512 & 0.075 & 0.000 & 0.503 & 0.080 & 0.000 & 0.401 & 0.078 & 0.000 & 0.375 & 0.085 & 0.000 & 0.408 & 0.090 \\
\hline K & 0.000 & 0.000 & 1.710 & 0.000 & 0.000 & 1.793 & 0.000 & 0.000 & 1.743 & 0.000 & 0.000 & 1.777 & 0.000 & 0.000 & 1.798 & 0.000 & 0.000 & 1.829 \\
\hline 总量 & 8.026 & 4.000 & 13.849 & 8.002 & 4.000 & 13.922 & 8.030 & 4.000 & 13.916 & 8.008 & 4.000 & 13.871 & 7.993 & 4.000 & 13.908 & 8.029 & 4.000 & 13.964 \\
\hline
\end{tabular}

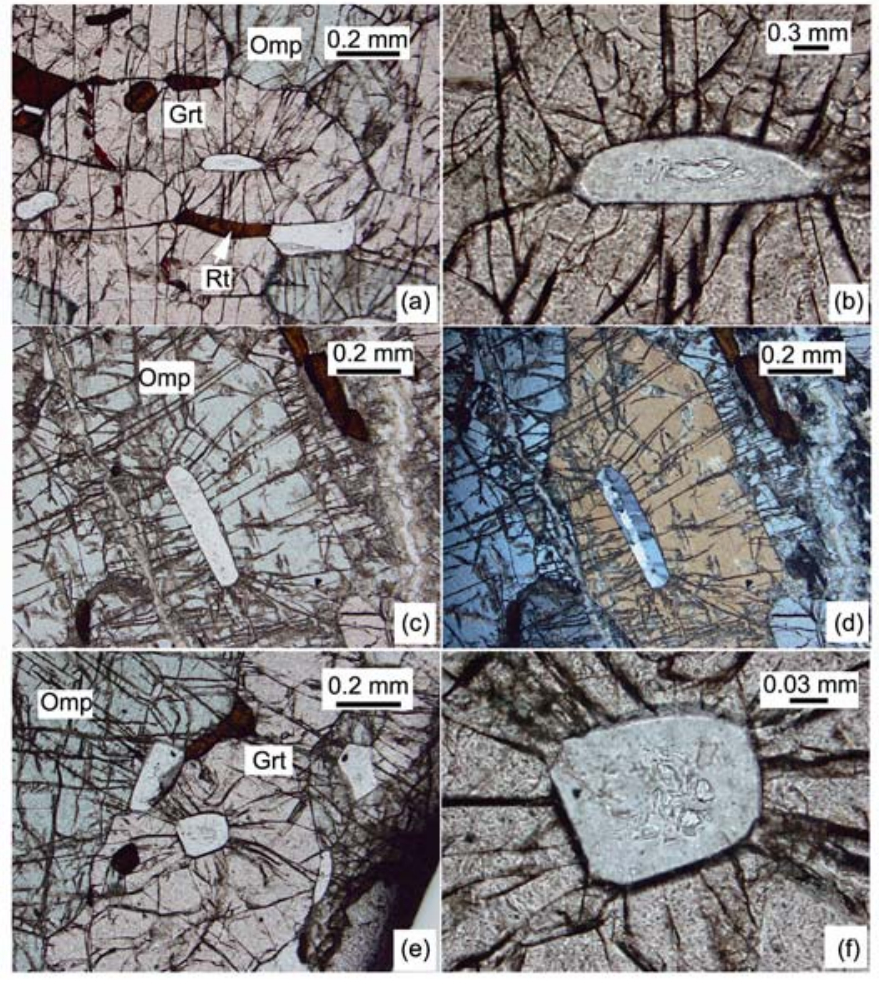

图 2 榴辉岩中柯石英和柯石英假象的显微结构特征 (a)和(b) 榴辉岩石榴子石中的柯石英包体, 中心高突起的柯石 英被石英所围绕, (b)是(a)的局部放大(样品 Q07-8-2.3). (c)和(d) 榴辉岩绿辉石中的多晶石英包体, 具有典型的柾状结构, 代表 柯石英假象(样品 Q07-8-2.3). (e)和(f) 榴辉岩石榴子石中的柯石 英包体，柯石英残留被石英所围绕(样品 Q07-8-2.2) 

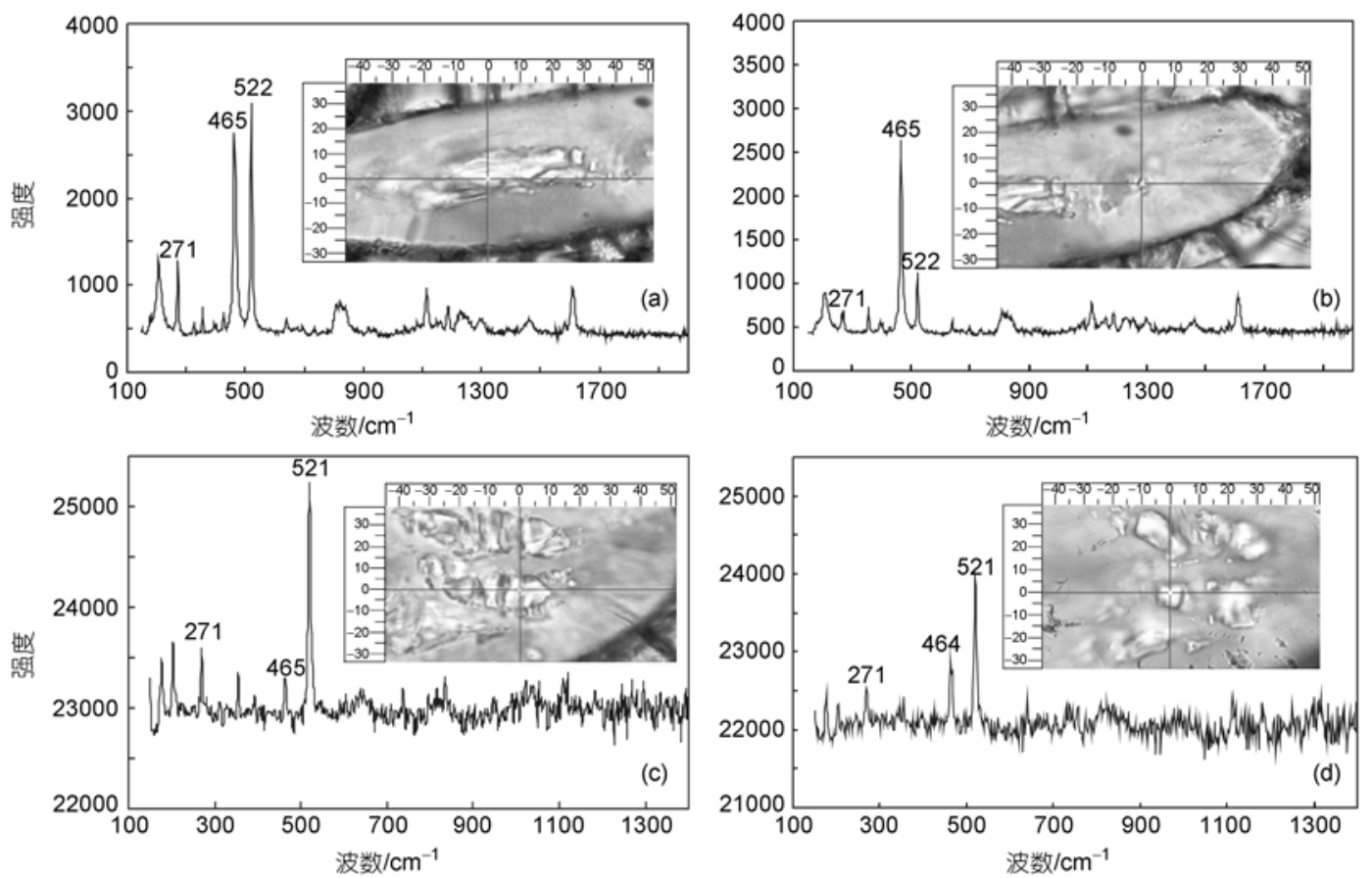

图 3 柯石英残留的拉曼光谱分析

(a)和(b)为样品 Q07-8-2.3; (c)和(d)为样品 Q07-8-2.2

曼光谱柯石英的峰相对变弱, 而石英峰较强(图 3).

\section{4 温压计算}

利用 Grt-Cpx-Phe矿物压力计 ${ }^{[27]}$ 和 Grt-Cpx矿物

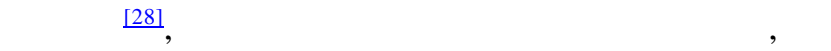
品Q07-8-2.3 的峰期温压条件为 $670 \sim 705^{\circ} \mathrm{C}$ 和 $2.7 \sim 3.05$ $\mathrm{GPa}$; 样品Q07-8-2.2 的温压条件为 $680 \sim 730^{\circ} \mathrm{C}$ 和 2.85 3.25 GPa (图 4), 比前者略高, 但总体上, 两个 样品的 $P-T$ 估算结果与榴辉岩中柯石英稳定存在一 致.

\section{5 讨论}

在所研究的两个样品中, 除柯石英残晶的包体 外，还具有大量多晶石英包体，且柯石英残晶的包体 和多晶石英包体可在同一薄片中出现(图 2), 能谱分 析显示它们均为纯的 $\mathrm{SiO}_{2}$, 围绕柯石英分布的多晶石 英和没有柯石英残留的多晶石英包体具有类似的栅 状结构特征, 这进一步说明这些纯的多晶石英包体 (不含钾长石)应为柯石英转变而成. 然而, 值得注意 的是, 除了由纯的 $\mathrm{SiO}_{2}$ 组成的多晶石英包体外, 在同 一样品中, 还发现一些在母矿物中形成典型放射状
裂纹的包体, 在这些包体中, 除多晶石英外, 还共生 有细粒的钾长石集合体，早期在柴北缘都兰地区和 南阿尔金地区所报道的多晶石英包体多是这种类型， 并也被认为是柯石英假象 ${ }^{[22,23]}$. Massonne $\mathrm{e}^{[24]}$ 认为这 种由石英和钾长石集合体组成的包体不能简单看成 是柯石英的假象, 而解释其为先前的 K-cymrite转变 而成. 无论如何, 石英-钾长石集合体包体与含柯石 英残留的包体同时出现说明前者也可能是早期超高 压变质相转变而成, 但其转变前的矿物特征及其转 变过程还需进一步研究.

在柴北缘地区, 除都兰榴辉岩-片麻岩单元外, 在其西端的鱼卡-落凤坡和锡铁山榴辉岩-片麻岩单 元的榴辉岩和其围岩中, 还没有发现任何柯石英及 具有柯石英假象特征的多晶石英包体, 甚至也没有 多晶石英+钾长石的包体存在, 我们柴北缘西端含多 硅白云母榴辉岩所进行的温压计算显示其峰期变质 条件总体上稳定在柯石英/石英转变线以下 ${ }^{[8,9]}$. 到目 前为止, 在柴北缘地区具有明确的超高压变质作用 证据仅发现在都兰地区的榴辉岩和片麻岩以及绿梁 山地区的石榴橄榄岩中. 因此, 柴北缘地区很可能并 
不像中国东部的大别-苏鲁超高压变质带那样存在巨 量物质的深俯冲, 可能仅仅少量的岩石经历过UHP
变质作用, 而大部分岩石仅仅经历过HP变质作用. 当然, 这还需要进一步详细的研究工作来确认.
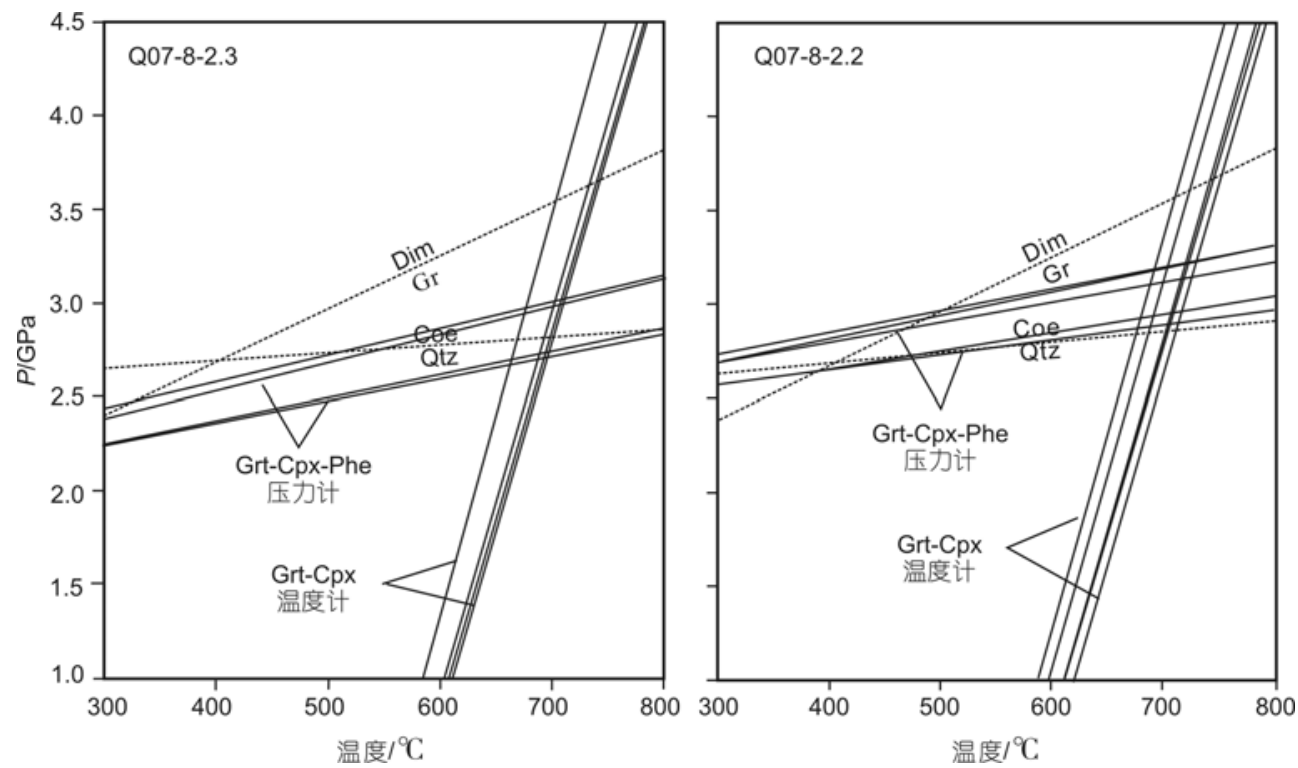

图 4 含柯石英榴辉岩的温压估算结果

Grt-Cpx-Phe压力计据文献[27]; Grt-Cpx温度计据文献[28]

致谢审稿人提出了建设性修改意见, 在此表示感谢.

\section{参考文献}

1 Yang J J, Deng J F. Garnet peridotites and eclogites in the Northern Qaidam Mountains, Tibetan plateau: A first record. In: Ernst W G, Liou J G, eds. First Workshop on UHP Metamorphism and Tectonics. Stanford: ILP Task Group III-6, Stanford University, 1994. A-20

2 杨经绥, 许志琴, 李海兵, 等. 柴北缘地区榴辉岩的发现及潜在的地质意义. 科学通报, 1998, 43(14): 1544一1549

3 杨经绥, 宋述光, 许志琴, 等. 柴北缘早古生代高压-超高压变质带发现典型超高压矿物——柯石英. 地质学报, 2001, 75(2): 175 $-179$

4 Yang J S, Xu Z Q, Zhang J X, et al. Early Palaeozoic North Qaidam UHP metamorphic belt on the north-eastern Tibetan plateau and a paired subduction model. Terra Nova, 2002, 14(5): 397-404[이]

5 Yang J S, Liu F L, Wu C L, et al. Two Ultrahigh-pressure metamorphic events recognized in the central orogenic belt of China: Evidence from the U-Pb dating of coesite-bearing zircons. Int Geol Rev, 2005, 47: 327-343 [doi]

6 张建新, 杨经绥, 许志琴, 等. 柴北缘榴辉岩的峰期和退变质年龄: 来自 U-Pb 及 $\mathrm{Ar}-\mathrm{Ar}$ 同位素测定的证据. 地球化学, 2000, 29(3): $217-222$

7 张建新, 孟繁聪, 杨经绥. 柴北缘西段榴辉岩相的变质泥质岩: 榴辉岩与围岩“原地” 关系的证据. 中国科学 D 辑: 地球科学, 2004, 34(9): 825-834

8 张建新, 孟繁聪, 杨经绥. 柴北缘榴辉岩的 PT 演化历史. 岩石矿物学杂志, 2005, 24 (4): 245-254

9 Zhang J X, Yang J S, Mattinson C G, et al. Two contrasting eclogite cooling histories, North Qaidam HP/UHP terrane, western China: Petrological and isotopic constraints. Lithos, 2005, 84: 51-76 [1] $\underline{\text { doi] }}$

10 Zhang J X, Yang J S, Meng F C, et al. U-Pb isotopic studies of eclogites and their host gneisses in the Xitieshan area of the North Qaidam Mountains, western China: New evidence for an early Paleozoic HP-UHP metamorphic belt. J Asian Earth Sci, 2006, 28: 143-150[doi]

11 Song S G, Yang J S, Xu Z Q, et al. Metamorphic evolution of the coesite-bearing ultrahigh-pressure terrane in the north Qaidam, northern Tibet, NW China. J Metamorph Geol, 2003, 21: 631-644 [doi] 
12 Song S, Zhang L, Niu Y, et al. Geochronology of diamond-bearing zircons from garnet peridotite in the North Qaidam UHPM belt, Northern Tibetan Plateau: A record of complex histories from oceanic lithosphere subduction to continental collision. Earth Planet Sci Lett, 2005, 234: 99-118 $\underline{\text { [doi] }}$

13 Song S, Zhang L, Niu Y, et al. Evolution from oceanic subduction to continental collision: A case study of the Northern Tibetan Plateau inferred from geochemical and geochronological data. J Petrol, 2006, 47: 435-455[ [doi]

14 Song S, Zhang L, Niu Y. Ultra-deep origin of garnet peridotite from the North Qaidam ultrahigh-pressure belt, Northern Tibetan Plateau, NW China. Am Mineral, 2004, 89: 1330-1336

15 Zhang G, Song S, Zhang L, et al. The subducted oceanic crust within continental-type UHP metamorphic belt in the North Qaidam, NW China: Evidence from petrology, geochemistry and geochronology. Lithos, 2008, 104: 99-118 [doi]

刘良，车自成，罗金海，等. 阿尔金山西段榴辉岩的确定及地质意义. 科学通报, 1996, 41(14): 1485-1488

刘良, 孙勇, 校培喜, 等. 阿尔金发现超高压(>3.8 Ga) 石榴二辉橄榄岩. 科学通报, 2002, 47(9): 657-662

刘良, 陈丹玲, 张安达, 等. 阿尔金超高压 $(>7 \mathrm{GPa})$ 片麻状(含)钾长石辉石岩一一石榴子石出熔单斜辉石的证据. 中国科学 D 辑: 地球科学, 2005, 35(2): 105-114

19 Zhang J X, Zhang Z M, Xu Z Q, et al. Petrology and geochronology of eclogites from the western segment of the Altyn Tagh, northwestern China. Lithos, 2001, 56: 189-208

20 Zhang J X, Mattinson C G, Meng F C, et al. An Early Palaeozoic HP/HT granulite-garnet peridotite association in the south Altyn Tagh, NW China: P-T history and U-Pb geochronology. J Metamorph Geol, 2005, 23: 491-510[doi]

21 Zhang J X, Mattinson C G, Meng F C, et al. Polyphase tectonothermal history recorded in granulitized gneisses from the North Qaidam HP/UHP metamorphic terrane, Western China: Evidence from zircon U-Pb geochronology. Geol Soc Am Bull, 2008, 120: 732$749 \underline{\underline{\text { doi }]}} \sim$

22 张建新, 杨经绥, 许志琴, 等. 阿尔金榴辉岩中超高压变质作用证据. 科学通报, 2002, 47(3): 231-234

宋述光，杨经绥. 柴北缘都兰地区榴辉岩中透长石十石英包裹体: 超高压变质作用的证据. 地质学报, 2001, 75(2): 180-185

Massonne H J. First find of coesite in the ultrahigh-pressure metamorphic area of the central Erzgebirge, Germany. Eur J Mineral, 2001, 13: 565-570[doi]

Yang J J, Godard G, Simth D C. K-feldspar-bearing coesite pesudomorphs in an eclogite from Lanshantou (Eastern China). Eur J Mineral, 1998, 10: 969-985

Kretz R. Symbols for rock-forming mineral. Am Mineral, 1983, 68: 277-279

Ravna E J K, Terry M P. Geothermobarometry of UHP and HP eclogites and schists_- An evaluation of equilibria among garnetclinopyroxene-kyanite-phengite-coesite/quartz. J Metamorph Geol, 2004, 22: 579-592[doi]

Ravna E K. The garnet-clinopyroxene $\mathrm{Fe}^{2+}-\mathrm{Mg}$ geothermometer: An updated calibration. J Metamorph Geol, 2000, 18: 211-219[doi] 